\title{
DEVELOPMENT OF ROBOT FOR SURVEYING AND \\ INVESTIGATING OUTPUT OF HARBOR STRUCTURES
}

\author{
(Measurement Equipment of Completed Amount of Block Installation) \\ Masami Onizawa, Masashi Itamura, Yoshiaki Ikeda \\ Construction Machinery Center \\ Hokkaido Development Bureau \\ 2-8, Tukisamu-higashi \\ Toyohiraku, Sapporo, Japan 062
}

\begin{abstract}
In this paper, the development of the three-dimensional survey robot system using a helicopter by radio-control or a semisubmerged low rolling type survey boat for the purpose of mainly labor saving in the management of the output of construction works among the construction of the structures for harbor works and for the use of surveying underwater and water-surface structures is reported.
\end{abstract}

1. Foreword

Harbors have main facilities such as breakwaters, courses, anchorages, and moorings. When these facilities are constructed, breakwater construction is very important in order to keep rough waves from entering a harbor.

Breakwaters are usually constructed in a wave dissipating structure which uses special concrete blocks. Supervision of the completed amount of the blocks is carried out in above-water and underwater parts. At present the above-water part is measured manually by the workers in charge and the underwater part by divers using such devices as a staff and a transit.

As the size of special concrete blocks increases, concaves, convexes, and space between blocks become larger. Therefore, the completed amount measuring procedure becomes much more dangerous and difficult.

To solve this problem, development of completed block installation amount measurement equipment is highly expected, for the purposes of safety promotion, efficiency promotion, and labor reduction in the measuring procedure.

The Ministry of Transport appropriates funds for constructing work boats and institutionalizes development experiments in order to promote the technological development of harbor constructing machines. The Construction Machine Manufacturing Department of the Hokkaido Development Bureau is in charge of the development of completed block installation amount measurement equipment. The development was implemented by the department for 4 years from 1987 to 1990 . The outline of the development is introduced below.

2. Purpose of the Development

The purpose of measurement equipment development is to develop an automatic and remote control system with the following elements:

* Depth of water and range in measuring:

Up to approximately $20 \mathrm{~m}$ deep. All faces of completed block installation amount.

* Blocks as an object of measurement:

Various kinds of special concrete blocks weighing 2-50 tons.

* Development policy of measurement equipment:

Measurement equipment which measures the faces of special concrete blocks without contact.

According to the above purpose, the outline of measurement equipment in the technology development program is defined as a system which consists of subsystems such as an above-water subsystem, an underwater subsystem, and a data processing unit. The reason for dividing the system into subsystems is that objects to be 
An RC (radio-controlled) measuring boat with self-attitude control equipment plays a central part in the underwater subsystem. In both subsystems, three-dimensional position coordinates are measured by using an autotracking distance sensor.

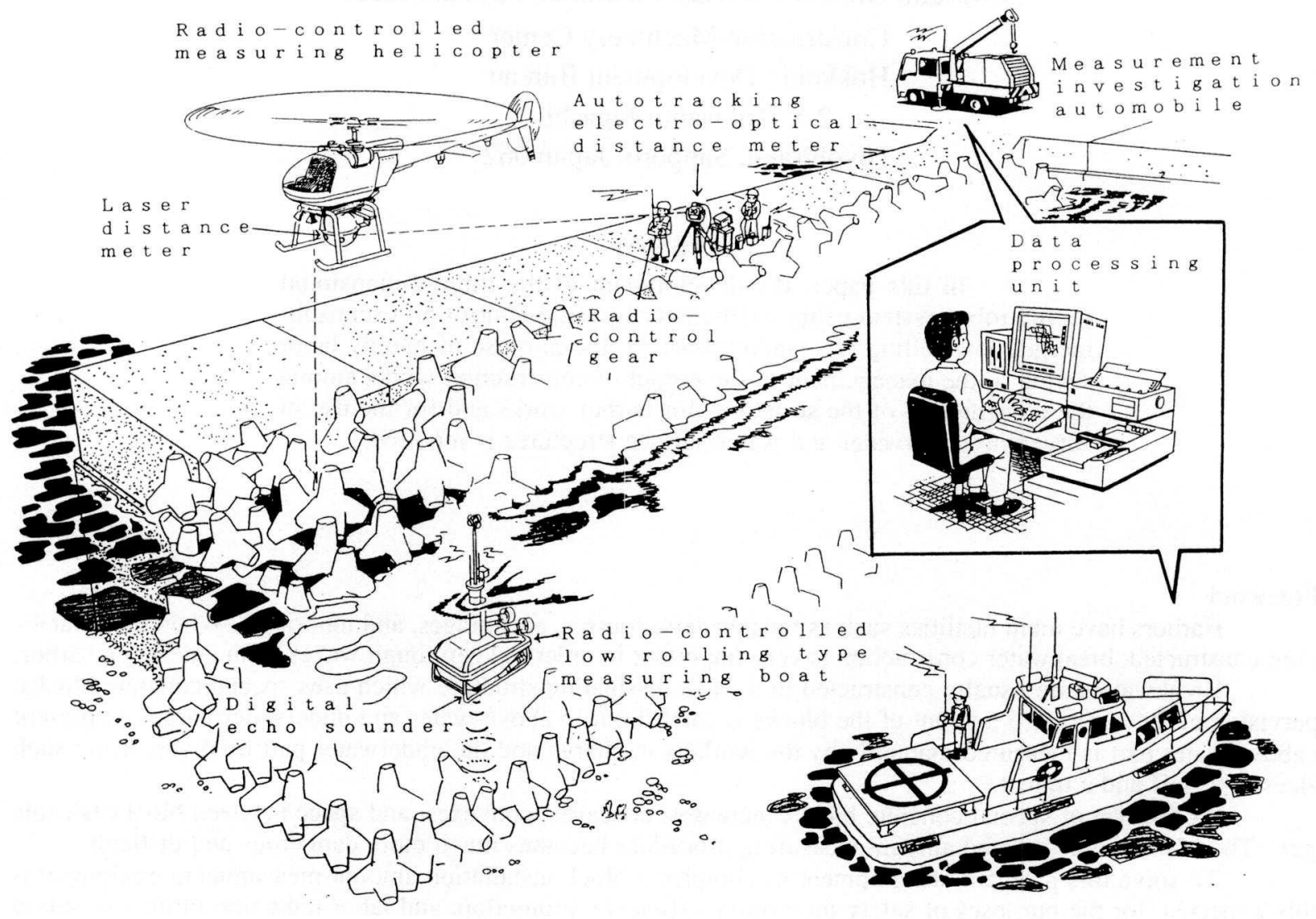

Figure 1 Outline of the completed block installation amount measurement equipment

\section{Circumstances of the Development}

Hokkaido Development Bureau has engaged in measuring methods of installing special concrete blocks since the 1970s. The object of the research was methods of manual measurement. The completed block installation amount measurement equipment was developed and realized by taking advantage of past research material and by investigating the current actual conditions of construction management. The following problems were solved year by year in the process of the development.

3.11987

After examining various sensors, most effective ultrasonic and pressure sensors were chosen as measurement sensors for use in above-water and underwater subsystems. Studies of their performances proved that the ultrasonic sensor is the best for the underwater subsystem.

3.21988

The principal object was to develop an above-water measurement subsystem. Experiments were performed to develop air-support measurement equipment. The experiments showed that laser sensors, RC helicopters, and electro-optical distance sensors as three-dimensional position measurement equipment are effective.

3.31989

In order to complete an above-water measurement subsystem, efforts were made to develop more advanced laser distance sensors, RC helicopters for measurement, and three-dimensional position measurement equipment using an autotracking electro-optical distance sensor. 
In order to complete an underwater measurement subsystem, efforts were made to develop a better digital echo sounder and an RC low-rolling-type measuring boat. In the sea, a comprehensive experiment was performed on the "completed block installation amount measurement equipment," which consists of above-water and underwater subsystems and a data processing unit.

\section{Composition of Measurement Equipment}

The measurement equipment system consists of above-water and underwater subsystems. The abovewater subsystem consists of an RC helicopter, a laser distance sensor, and three-dimensional position measurement equipment and a data processing unit. The underwater subsystem consists of an RC measuring boat, a digital echo sounder, and the three-dimensional position measurement equipment and data processing unit shared with the above-water subsystem. The diagram of the system is shown in Fig. 2.

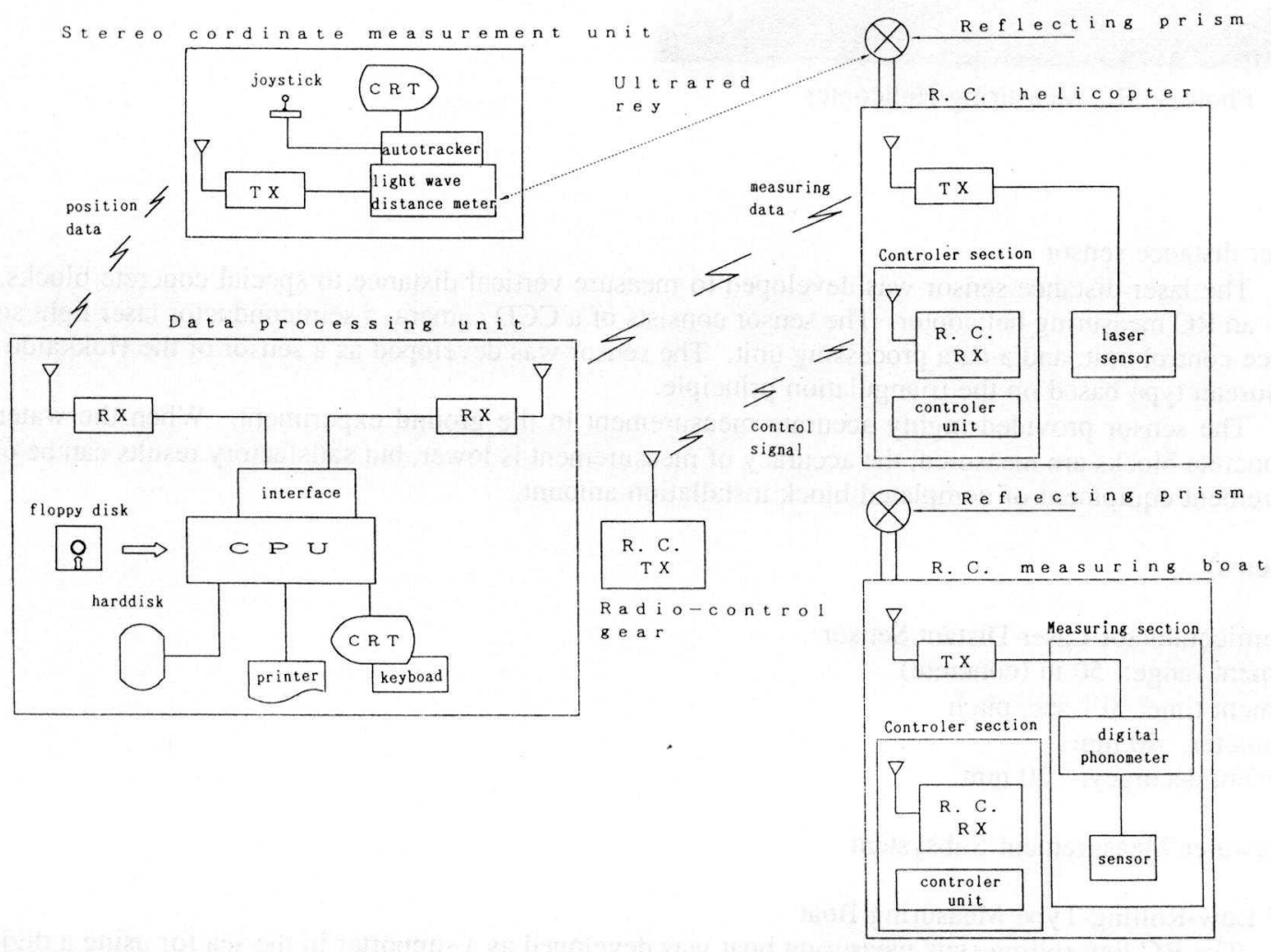

Figure 2 Diagram of the completed block installation amount measurement equipment system

\subsection{Above-Water Measurement Subsystem}

\subsubsection{RC measuring helicopter}

The RC measuring helicopter was developed as a supporter in the air for using a laser distance sensor. This measuring helicopter is subjected to rolling and pitching caused by wind over the sea. Therefore, a self-attitude control function is essential to keep the attitude of the helicopter stable. As self-attitude control equipment, a vibration gyro, an accelerometer, and strap-down-type inertial measurement equipment using magnetic direction sensor are adopted. The equipment is useful to keep the attitude of the helicopter stable when flying at various speeds, and ease the burden of operators. Below are the major items and a photo of the complete view. 


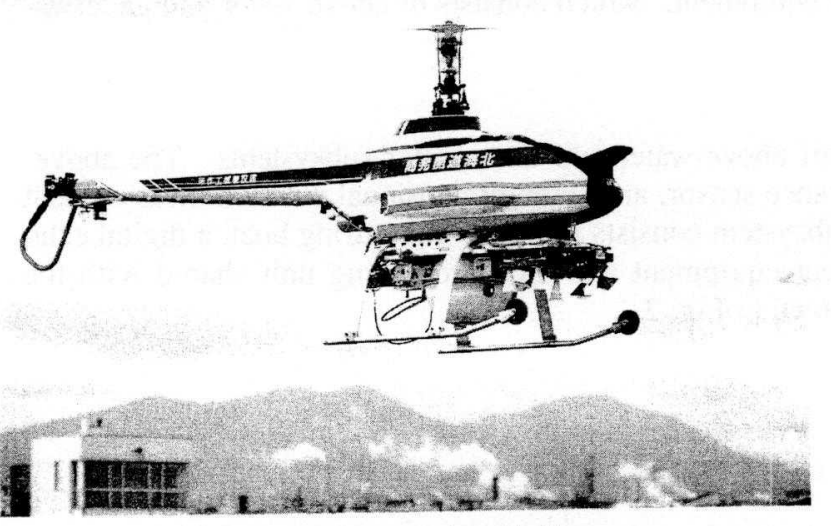

Photo 1 RC Measuring Helicopter
(Major Items)

Type: RC helicopter of self-attitude control type Body length: approx. $2.6 \mathrm{~m}$

Body weight: approx. $67 \mathrm{~kg}$

Body control: 3 degrees (in direction angle, roll angle, and pitch angle)

Flight duration: $30 \mathrm{~min}$. (maximum)

\subsubsection{Laser distance sensor}

The laser distance sensor was developed to measure vertical distance to special concrete blocks, and is carried by an RC measuring helicopter. The sensor consists of a CCD camera, a semiconductor laser light source, a light source control unit, and a data processing unit. The sensor was developed as a sensor of the Hokkaido Development Bureau type based on the triangulation principle.

The sensor provided highly accurate measurement in the ground experiment. When the waterline of special concrete blocks are measured, the accuracy of measurement is lower, but satisfactory results can be obtained as measurement equipment of completed block installation amount.

(Major Items)

Type: Semiconductor Laser Distant Sensor Measurement range: $50 \mathrm{~m}$ (concrete)

Measurement time: $0.1 \mathrm{sec}$. pitch

Beam diameter: $40 \mathrm{~mm}$

Measurement accuracy: $20 \mathrm{~mm}$

\subsection{Underwater Measurement Subsystem}

\subsubsection{RC Low-Rolling-Type Measuring Boat}

The RC low-rolling-type measuring boat was developed as a supporter in the sea for using a digital echo sounder. The measuring boat is a half-submerged type. Approximately $2 / 3$ of the total boat height is submerged to decrease pitch and roll caused by waves. Water resistance is decreased due to the streamlined shape of the boat. High density installation of onboard equipment made the boat smaller. The boat is equipped with four $500 \mathrm{~W}$ electric thrusters (approx. $10 \mathrm{~kg}$ driving force) on the stern.

Besides the characteristics of the boat shape, as in the case of the supporter in the air, an automatic selfattitude control system is adopted to decrease pitch and roll caused by waves. Such self-attitude control is achieved by a data processing unit which mixes displacement signals detected by a magnetic direction sensor and by a threeaxial direction rate sensor (vibration gyro), and operation signals sent by RC transmitter. Such aspects as attitude, direction, movement, and stop are dealt with by electric thrusters. 
(Major Items)

Type: Half-submerged Low-Rolling-Type (made by GFRP) Dimensions: $2.0 \mathrm{~m}(\mathrm{~L}) \times 1.3 \mathrm{~m}(\mathrm{~B}) \times 2.0 \mathrm{~m}(\mathrm{H})$

Draft: $1.4 \mathrm{~m}$

Displacement: $700 \mathrm{~kg}$

Speed: 2 Knots (maximum)

Duration: 1.5 hours (maximum charge and $100 \%$ output)

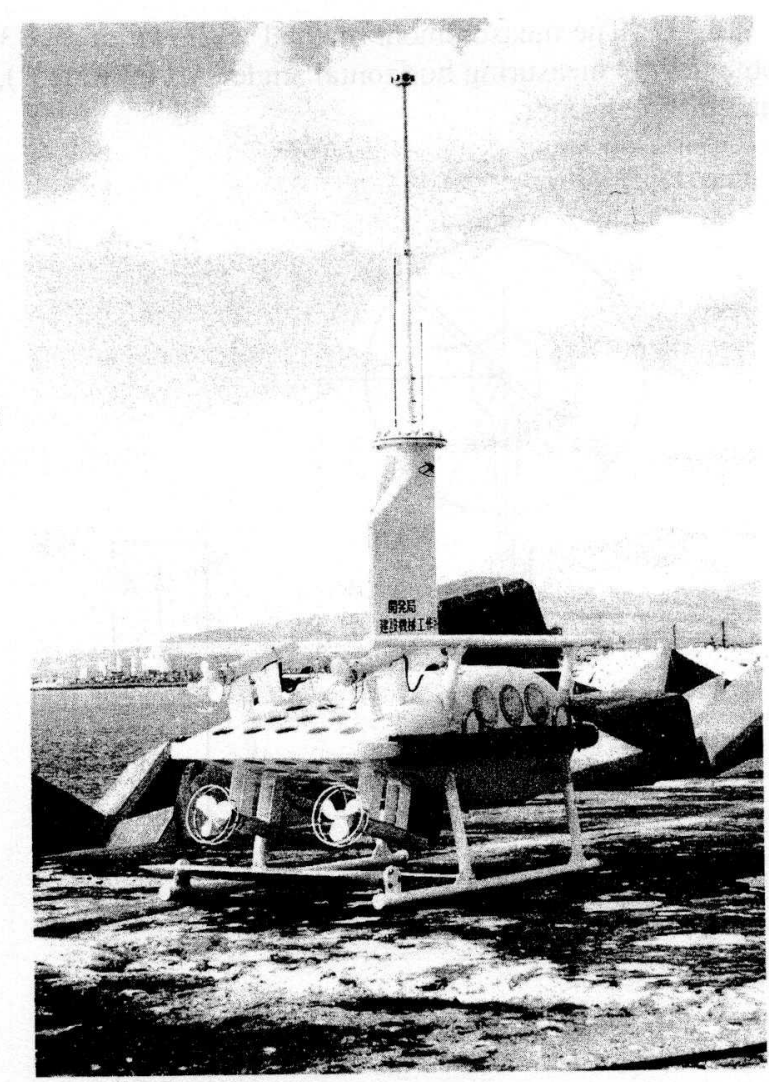

Photo 2 RC Low-Rolling-Type Measuring Boat

\subsubsection{Digital Echo Sounder}

The digital echo sounder is affixed to the boat bottom to measure vertical distance to special concrete blocks underwater. Conventional types of echo sounders used for harbor construction work are not appropriate for measuring the installation faces of special concrete blocks underwater. Therefore, the digital echo sounder was developed with emphasis on the following technical performances.

* To make precise measurements by beaming ultrasonic waves in sharp directional angles.

* To adjust the suppression and sensitivity of side lobes because the sounder is used for measurement directly under the boat.

As a result, the digital echo sounder can beam ultrasonic waves in directional angles one-fifth of the conventional types, and its measurement accuracy is within $4 \mathrm{~cm}$ at a depth of $10 \mathrm{~m}$.

Gimbal structure is adopted in the ultrasonic waves transmitter and receiver of the digital echo sounder, and keeps the sensor faced vertically underwater.

(Major Items)

Type: Precision Digital Echo Sounder

Measurement range: $0.6 \mathrm{~m}-40 \mathrm{~m}$ (under the transmitter and receiver)

Measurement time: $0.2 \mathrm{sec}$. continuous output

Directional angles: 3 degrees (half value / entire angle)

Gimbal angles: 8 degrees

Measurement accuracy: $(0.03+$ depth $/ 1000) \mathrm{m}$

\subsection{Three-dimensional Position Measurement Equipment}

An autotracking electro-optical distance meter is adopted to detect the position of the RC helicopter and the RC measuring boat, supporters of the sensors. This autotracking distance meter makes it unnecessary to adjust the sight and plays a very important role in labor saving. 
The measurement method is shown in Fig. 3. In the measurement method, the position of a supporter is obtained by measuring horizontal angle ( ), elevation ( ), and diagonal distance (L) of the supporter against the slope line of breakwater.
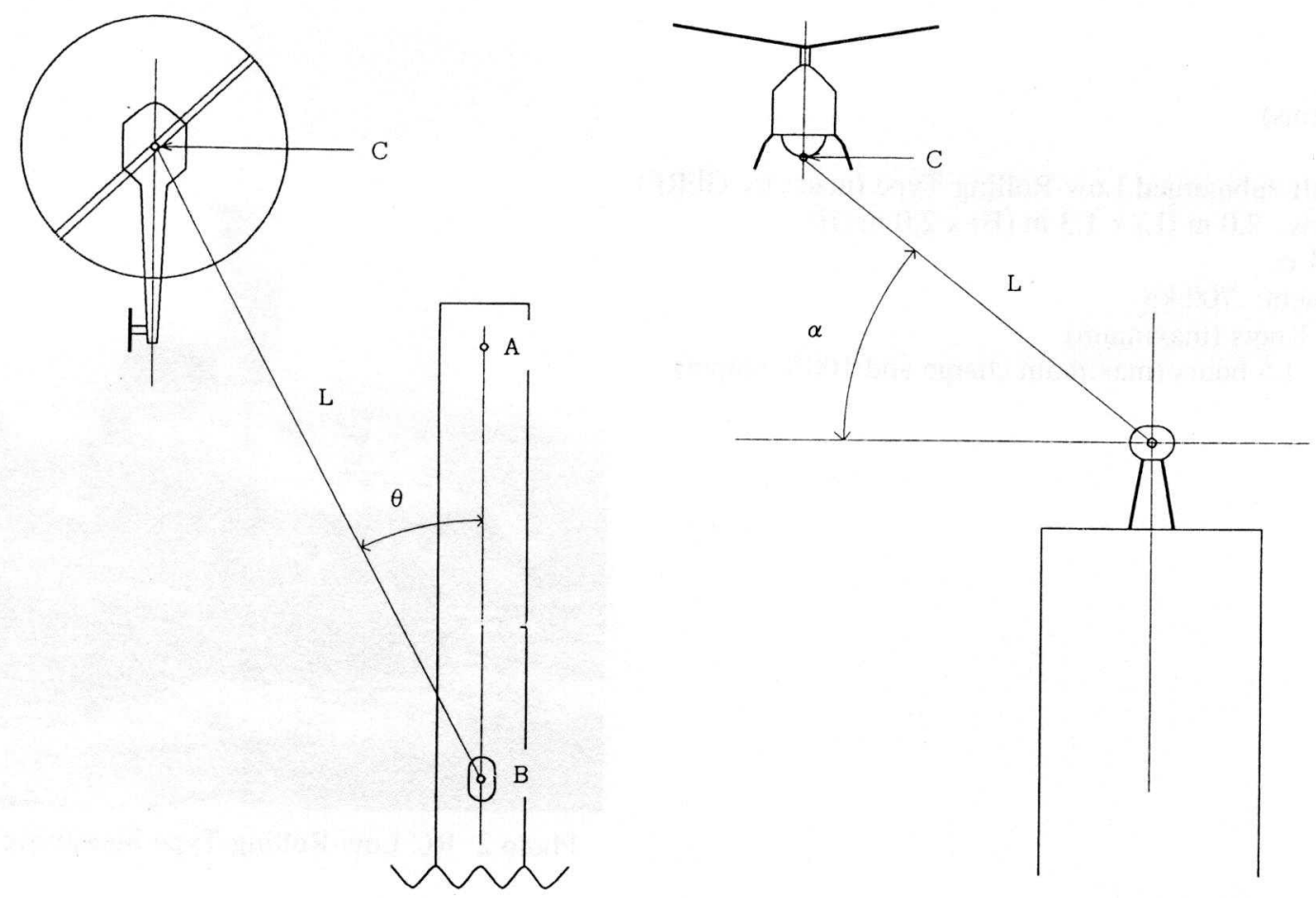

Figure 3 Application of Three-dimensional Position Coordinate Measurement Equipment

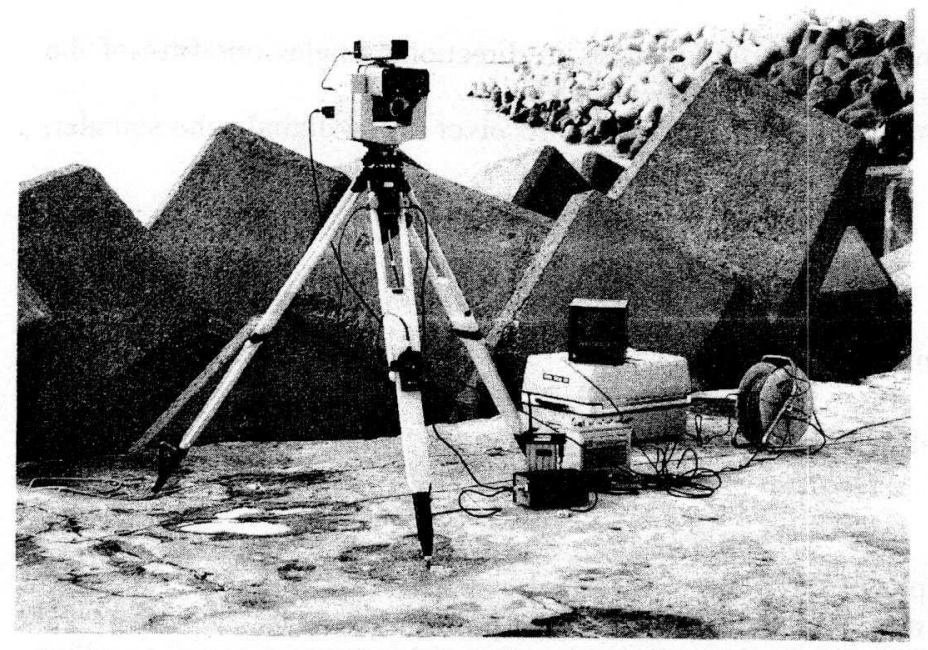

(Major Items)

Type: Geogymeter $140 \mathrm{~T}$ Type

Measurement range: $2500 \mathrm{~m}$ ( 1 element)

Measurement accuracy: $1 \mathrm{~cm}$ (for $1 \mathrm{~km}$ )

Angle accuracy: 3 seconds

Measurement time: $0.8 \mathrm{sec}$. pitch continuation Tracking speed: $34 \mathrm{~km} / \mathrm{h}$ (maximum)

Photo 3 Three-dimensional position measurement equipment 


\subsection{Data Processing Unit}

Data sent by radio from various measurement sensors and three-dimensional position measurement equipment is processed, displayed, and output by the data processing unit. The data processing unit consists of hardware, software, and data transmitting equipment based on personal computers.

This unit can output various information, such as a diagram of completed block installation and flight and sailing records of supporters.

\section{Field Test}

Experimental model of the completed block installation amount measurement equipment was put to practical field test in the sea. The test consisted of a preliminary test in which the flat part was measured and a main test in which the faces of special concrete blocks were measured respectively by the above-water subsystem and the underwater subsystem. Outlines of the tests are given below.

Experiment site:

Caisson yard and breakwater of Tomakomai West Port, Hokkaido

Experiment dates:

November 10, 1991 to November 26, 1991

\subsection{Preliminary Test}

The preliminary test was carried out to confirm whether the above-water and underwater subsystems, the three-dimensional position measurement equipment, and the data processing unit worked properly. In the test, the above-water and underwater flat parts were measured.

Satisfactory results were obtained for each piece of equipment.

In the case of the flat part measurement, slight measurement errors were observed (the slant of each measurement sensor beam makes the measured values larger than the actual vertical distance, but satisfactory results were obtained.

\subsection{Main test}

The main test was carried out to measure the completed block installation amount of 20-ton special concrete blocks installed at random at the caisson yard and breakwater of Tomakomai West Port.

\subsubsection{Above-water Measurement}

Measurement was done by the RC helicopter flying above the special concrete blocks along the breakwa-

ter.

\subsubsection{Underwater Measurement}

Measurement was done by the RC low-rolling measuring boat sailing over the special concrete blocks.

Measurement was possible in spite of rather strong winds and swells during the test period. Satisfactory results were obtained in the test, although strong winds and swells made it impossible to measure in the vicinity of the wave dissipation zone. The self-attitude control function of each supporter worked well and enabled operators to keep stable operation of the supporters under rather bad conditions.

As examples of the measurement results, the two-dimensional cross section and the three-dimensional projection chart are shown in Fig. 4 and Fig. 5. 


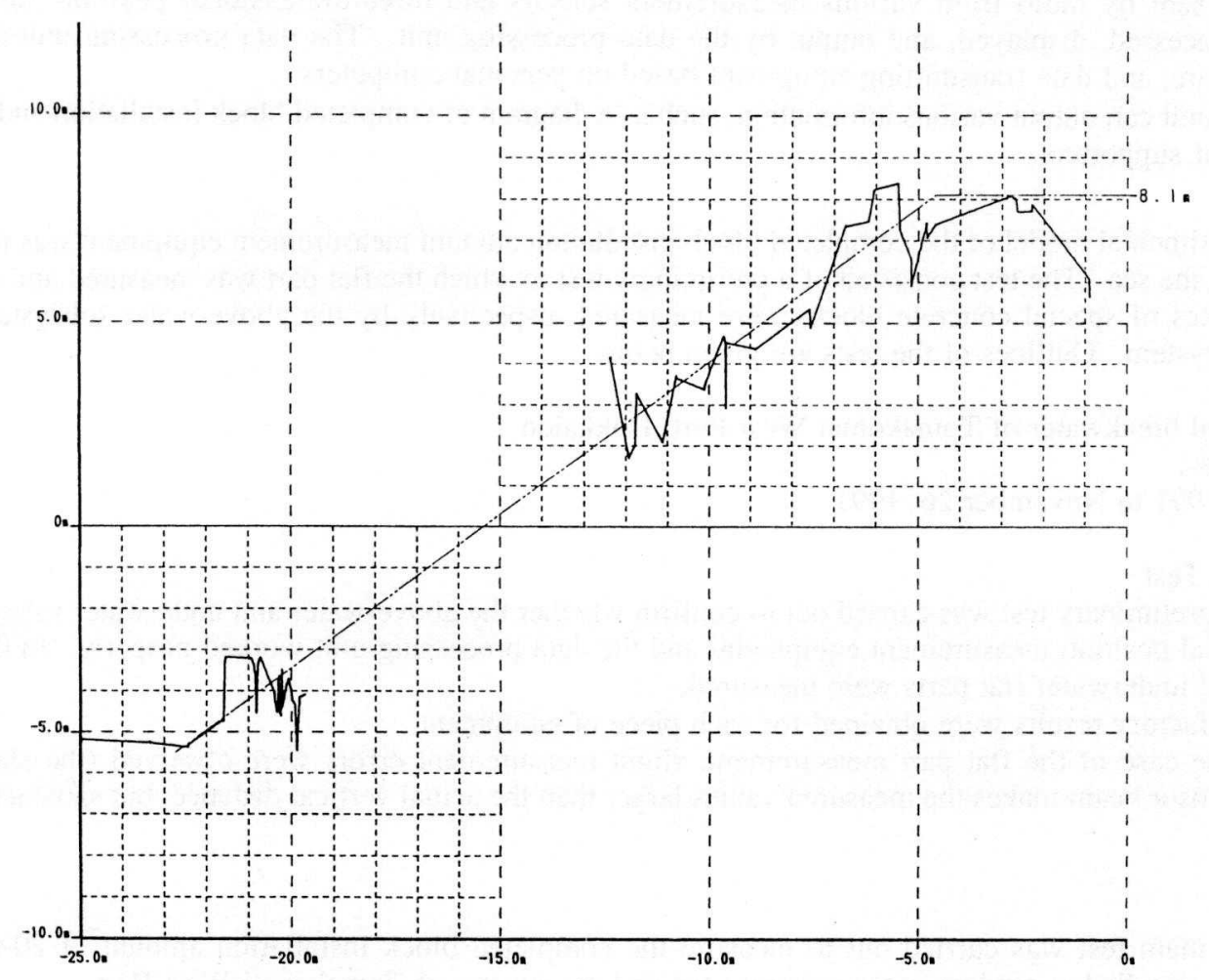

Figure 4 Two-dimensional cross section of the completed block installation amount

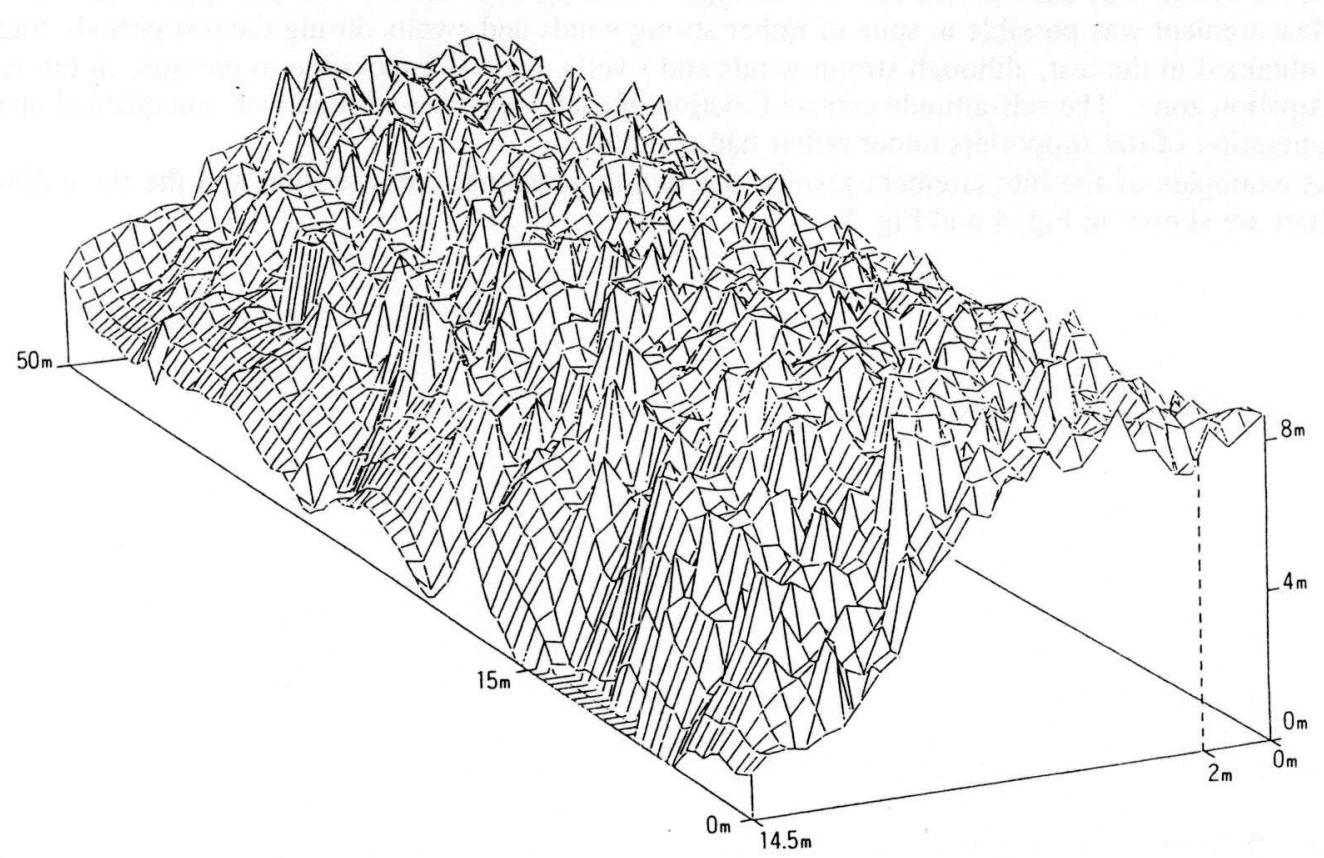

Figure 5 Three-dimensional projection chart(above-water) 


\section{Postscript}

We obtained satisfactory results in automatization, remote control, and safety promotion of measurement work through the development of the completed block installation amount measurement equipment. We will try to develop equipment which is easier to operate and to confirm the durability of the equipment, and will conduct research regarding the possibility of using the equipment for general purposes.

This completed block installation amount measurement equipment can be used for not only measurement of special concrete blocks, but also for such purposes as disaster investigation, and measurement of pre- or postdredged parts, riprapped and leveled parts, and the changing conditions of structures.

With the availability of the completed block installation amount measurement equipment, the equipment is expected to make a great contribution to the promotion of safety in harbor construction and to the promotion of construction management. 